\title{
Glutathione S-transferase omega in the lung and sputum supernatants of COPD patients \\ Terttu H Harju ${ }^{1}$, Mirva J Peltoniemi ${ }^{1,2}$, Paula H Rytilä ${ }^{3}$, Ylermi Soini ${ }^{6,8}$, Kaisa M Salmenkivi ${ }^{4}$, Philip G Board ${ }^{5}$, Lloyd W Ruddock ${ }^{2}$ and Vuokko L Kinnula*7
}

\begin{abstract}
Address: ${ }^{1}$ Department of Internal Medicine, University of Oulu, Oulu, Finland, ${ }^{2}$ Biocenter Oulu and Department of Biochemistry, University of Oulu, Oulu, Finland, ${ }^{3}$ Department of Medicine, Division of Allergology, University of Helsinki, Helsinki, Finland, ${ }^{4}$ Department of Pathology, Helsinki University Hospital, Helsinki, Finland, ${ }^{5}$ John Curtin School of Medical Research, Australian National University, Canberra, Australia, ${ }^{6}$ Department of Pathology, Oulu University Hospital, Oulu, Finland, ${ }^{7}$ Department of Medicine, Division of Pulmonary Diseases, University of Helsinki and Helsinki University Hospital, Helsinki, Finland and ${ }^{8}$ Department of Clinical Pathology and Forensic Medicine, University of Kuopio, Kuopio, Finland

Email: Terttu H Harju - terttu.harju@oulu.fi; Mirva J Peltoniemi - mirva.peltoniemi@oulu.fi; Paula H Rytilä - kpr@dlc.fi; Ylermi Soini - ylermi.soini@uku.fi; Kaisa M Salmenkivi - kaisa.salmenkivi@hus.fi; Philip G Board - philip.board@anu.edu.au; Lloyd W Ruddock - lloyd.ruddock@oulu.fi; Vuokko L Kinnula* - vuokko.kinnula@helsinki.fi

* Corresponding author
\end{abstract}

Published: 6 July 2007

Respiratory Research 2007, 8:48 doi:10.1 186/1465-992I-8-48

This article is available from: http://respiratory-research.com/content/8/I/48

(c) 2007 Harju et al; licensee BioMed Central Ltd.

This is an Open Access article distributed under the terms of the Creative Commons Attribution License (http://creativecommons.org/licenses/by/2.0), which permits unrestricted use, distribution, and reproduction in any medium, provided the original work is properly cited.

\begin{abstract}
Background: The major contribution to oxidant related lung damage in COPD is from the oxidant/antioxidant imbalance and possibly impaired antioxidant defence. Glutathione (GSH) is one of the most important antioxidants in human lung and lung secretions, but the mechanisms participating in its homeostasis are partly unclear. Glutathione-S-transferase omega (GSTO) is a recently characterized cysteine containing enzyme with the capability to bind and release GSH in vitro. GSTO has not been investigated in human lung or lung diseases.
\end{abstract}

Methods: GSTOI-I was investigated by immunohistochemistry and Western blot analysis in 72 lung tissue specimens and 40 sputum specimens from non-smokers, smokers and COPD, in bronchoalveolar lavage fluid and in plasma from healthy non-smokers and smokers. It was also examined in human monocytes and bronchial epithelial cells and their culture mediums in vitro.

Results: GSTOI-I was mainly expressed in alveolar macrophages, but it was also found in airway and alveolar epithelium and in extracellular fluids including sputum supernatants, bronchoalveolar lavage fluid, plasma and cell culture mediums. The levels of GSTOI-I were significantly lower in the sputum supernatants $(p=0.023)$ and lung homogenates $(p=0.003)$ of COPD patients than in nonsmokers.

Conclusion: GSTOI-I is abundant in the alveolar macrophages, but it is also present in extracellular fluids and in airway secretions, the levels being decreased in COPD. The clinical significance of GSTOI-I and its role in regulating GSH homeostasis in airway secretions, however, needs further investigations. 


\section{Background}

Several studies suggest the importance of oxidative stress in the pathogenesis of chronic obstructive pulmonary disease (COPD). Cigarette smoke not only contains high levels of oxidants, but it also activates oxidant producing pathways in the lungs [1,2]. The oxidant/antioxidant imbalance present in the lungs of these patients also results from the impaired capacity of the antioxidant/ detoxification enzymes to detoxify the harmful reactive oxygen metabolites [3-8]. Very little is known about specific changes in the major antioxidant defence mechanisms in mild or severe COPD.

One of the major antioxidants in human airways is glutathione (GSH) (L- $\gamma$-glutamyl-L-cysteinyl-glycine); however the regulatory mechanisms controlling the intra- and extra-cellular concentrations of GSH are not completely understood [9-11]. The rate limiting enzyme in GSH biosynthesis, glutamate cysteine ligase (GCL) is induced by cigarette smoke [12], but controversially shown to either increase or decrease in COPD $[5,13,14]$. GCL levels alone do not explain the changes observed in the free GSH levels of airways in smokers or COPD [7]. Other enzymes that can participate in GSH homeostasis in the lung and airway secretions include glutathione peroxidases (Gpx); for example Gpx2 is induced in experimental mice model by smoke exposure [15] and Gpx3 is increased in the bronchial epithelium and epithelial lining fluid of smokers [16]. Another additional group of enzymes that is associated with GSH homeostasis in human airways is glutaredoxin (Grx) family of enzymes. The classical member of this family, Grx1, is regulated in bronchial epithelial cells by oxidants and cigarette smoke in vitro [8], but has also been shown to be present in the extracellular fluids including sputum supernatants [17-19]. One important function of glutaredoxins is their thioltransferase activity and the subsequent effects on the glutathionylation state of proteins in the lung. It has become apparent that there is another thioltransferase i.e. glutathione-S-transferase omega (GSTO) in mammalian cells which may have potential role in regulating GSH homeostasis. This enzyme belongs to the glutathione-S-transferase family (GST) that detoxify toxic substrates present in tobacco smoke by a GSH-dependent mechanism [20,21]. GSTO contains an N-terminal glutathione-binding domain suggesting its role in the metabolism and maintenance of GSH levels in intact cells $[20,22]$. Since GSH is one of the major antioxidants of the airways, it can be hypothesized that GSTO may participate in the maintenance of GSH not only intracellularly, but also in the extracellular space and this may be modulated by oxidative stress.

The present study was undertaken 1) to investigate the cell specific distribution and expression of GSTO1-1 in healthy human lung, 2) to compare the GSTO1-1 expression patterns in the lung of non-smokers, smokers without obstruction and smokers with variable severities of COPD, 3) to assess whether GSTO1-1 is associated with COPD severity and 4) to analyze whether GSTO1-1 can be detected in airway secretions/induced sputum supernatants, bronchoalveolar lavage fluid (BALF) or plasma.

\section{Methods \\ Tissue, induced sputum, bronchoalveolar lavage and plasma specimens}

Lung tissue specimens from 72 patients including 26 current smokers with COPD, 22 current smokers with normal lung function, 16 life-long non-smokers undergoing resection for lung tumour (local carcinoma or hamartoma) and 8 ex-smokers with severe COPD undergoing lung transplantation were collected for immunohistochemical studies from the archives of the Departments of Pathology, Oulu University Hospital or Helsinki University Hospital. COPD was defined on the basis of preoperative lung function: FEV1/FVC less than $70 \%$ and no reversibility (bronchodilatation effect less than 12\%) according to GOLD criteria [23]. All lung transplant patients with stage IV COPD were receiving inhaled corticosteroid therapy. All smokers were current smokers with the exception of lung transplant patients, who were all exsmokers. The clinical characteristics of the patients in the immunohistochemical studies are shown in Table 1. Tis-

Table I: The characteristics of the patients in the immunohistochemistry studies

\begin{tabular}{lcccc}
\hline & Non-smoker $N=16$ & Smoker N $=22$ & COPD N $=34$ & P-value \\
\hline Age, years & $65(13)$ & $63(8)$ & $62(9)$ & $27: 7$ \\
Sex M:F & $8: 8$ & $17: 5$ & $38(13)^{*}$ & 0.543 \\
Pack-years & 0 & $46(19)$ & $55(23)$ & 0.103 \\
FEVI \%predicted & $98(15)$ & $90(10)$ & $56(15)$ & 0.000 \\
FEVI/FVC \% & $86(9)$ & $83(11)$ & $34(21)$ & 0.000 \\
MEF50\%pred & $94(24)$ & $80(37)$ & $64(27)$ & 0.000 \\
DCO \%pred & $91(15)$ & $78(14)$ & $72(24)$ & 0.000 \\
DCO/VA \%pred & $89(11)$ & $83(12)$ & & 0.004 \\
\end{tabular}

Mean (SD)

*In post-hoc comparison only the alpha-I-antitrypsin group differed from smokers and other COPD-groups with mean pack-years of I8 (SD 9) years. 
sues for the Western analyses had been frozen immediately in liquid nitrogen after the surgery, and homogenized in ice cold phosphate buffered saline (PBS); the clinical characteristics of these patients are presented in Table 2. A total of 8 patients in the COPD group (two patients with stage I-II COPD and 6 lung transplant cases with stage IV COPD) were receiving inhaled corticosteroid therapy. None of the subjects had received $\mathrm{N}$-acetylcysteine treatment.

Sputum was induced by inhalation of $4.5 \%$ hypertonic saline given at 5-minute intervals for a maximum of 20 minutes according to the guidelines of the European Respiratory Society's Task Force [24]. The characteristics of the patients selected for the studies on induced sputum specimens are shown in Table 3.

Bronchoalveolar lavage (BAL) had been obtained from 3 non-smokers and 3 smokers who had been investigated for minor respiratory symptoms of unknown etiology. Fiberoptic bronchoscopy for sampling BAL fluid was performed under local anaesthesia with lignocaine and the fluid was collected after installation of 10 aliquots of 20 $\mathrm{ml}$ from the right middle lobe. The cytocentrifuge preparation indicated a normal cell differential count with over $90 \%$ of the cells being macrophages. After centrifugation ( $400 \times \mathrm{g}$ for 15 minutes), the cells and supernatant were collected, frozen and stored at $-80 \mathrm{C}$.

Plasma samples were collected from 4 non-smokers, 4 healthy smokers and 4 patients with stage I-II COPD.

\section{Cell cultures}

Human histiocytic lymphoma (U937) cells were obtained from the American Type Culture Collection [25]. The cells were cultured in RPMI 1640 supplemented with $10 \%$ fetal bovine serum, 100 units $/ \mathrm{ml}$ penicillin, and $100 \mu \mathrm{g} / \mathrm{ml}$ streptomycin. Monocyte-macrophage differentiation was induced by phorbol 12-myristate 13-acetate (PMA) at concentrations of $100 \mathrm{ng} / \mathrm{ml}$. Human non-malignant bronchial epithelial (BEAS-2B) cells (American Type Cul- ture Collection, Rockville, MD, USA) were cultured in Bronchial Epithelial Growth Medium (BEGM) (Clonetics Corporation, Walkersville, MD, USA) and subcultured before reaching confluence.

\section{Immunohistochemistry and cytochemistry of GSTO I-I in the tissues and sputum specimens}

One tissue block from each patient was selected from peripheral lung. Four- $\mu \mathrm{m}$ sections were cut for immunohistochemical analysis. The sections were deparaffinized in xylene and rehydrated in a descending ethanol series. Endogenous peroxidase was blocked by incubating the sections in 3\% hydrogen peroxide in absolute methanol for 15 minutes. The sections were incubated with the primary antibody for GSTO1-1 using a dilution of 1:200. The immunostaining was done using the Histostain-Plus Kit (Zymed Laboratories Inc., San Francisco, CA), and the chromogen was aminoethyl carbazole (AEC) (Zymed Laboratories Inc.). In negative controls, the primary antibody was substituted with phosphate-buffered saline (PBS) or rabbit primary antibody isotype control from Zymed Laboratories Inc.

The number of macrophages was calculated using the Zeiss AxioHOME Morphometry program (Zeiss, Jena, Germany). GSTO-positive macrophages were counted by two techniques and by three investigators, first by calculating the number in 10 high power fields of the specimen (YS) and secondly by using the Zeiss AxioHOME Morphometry program (Zeiss) (PR, KS). Immunoreactivity was also assessed semiquantitatively by grading the staining intensity of the macrophages, bronchial, bronchiolar or alveolar epithelium or vascular endothelium as negative (0), weak (1) or moderate/intense (2) (YS). GSTO1-1 positive and negative cells in the sputum specimens were counted (400 cells/cytospin).

The cytospin samples were treated with Ortho Permeafix (Ortho Diagnostic Systems Inc., UK) and for immunostaining, Zymed ABC Histostain-Plus Kit was used according to the manufacturer's protocol. The samples were

Table 2: The characteristics of the patients in Western blotting for whole lung homogenates

\begin{tabular}{lcccc}
\hline & Non-smoker N $=9$ & Smoker N = & COPD N = I7 & P-value \\
\hline Age, years & $62(13)$ & $60(3)$ & $61(9)$ & 0.0917 \\
Sex M:F & $4: 5$ & $4: 1$ & $13: 4$ & 0.350 \\
Pack-years & 0 & $41(14)$ & $35(15)^{*}$ & 0.000 \\
FEVI \%predicted & $99(20)$ & $84(14)$ & $50(28)$ & 0.000 \\
FEVI/FVC \% & $88(6)$ & $81(7)$ & $35(17)$ & 0.008 \\
MEF50\%pred & $94(29)$ & $84(61)$ & $57(20)$ & 0.009 \\
DCO \%pred & $92(18)$ & $88(11)$ & $61(22)$ & 0.002 \\
DCO/VA \%pred & $98(18)$ & $88(1)$ & 0.002
\end{tabular}

Mean (SD)

*In post-hoc comparison no significant differences were found between smokers and the COPD-groups considering pack-years. 
Table 3: The characteristics of the patients in the sputum study

\begin{tabular}{|c|c|c|c|c|}
\hline & Non-smoker $\mathrm{N}=6$ & Smoker $N=5$ & COPD N = 15 & $\mathrm{P}$-value \\
\hline Age, years & $59(3)$ & $52(6)$ & $63(8)$ & 0.06 \\
\hline Sex M:F & $4: 2$ & $4: 1$ & $8: 7$ & 0.103 \\
\hline Pack-years & 0 & $28(\mathrm{II})$ & $47(12)$ & 0.000 \\
\hline FEVI \%predicted & $107(6)$ & $102(15)$ & $62(18)$ & 0.001 \\
\hline FEVI/FVC \% & $83(5)$ & $82(5)$ & $64(10)$ & 0.001 \\
\hline MEF50 \%pred & $99(12)$ & $103(12)$ & $31(19)$ & 0.001 \\
\hline DCO \%pred & $96(10)$ & $84(13)$ & $65(12)$ & 0.001 \\
\hline DCO/VA \%pred & $101(12)$ & $102(6)$ & $76(17)$ & 0.003 \\
\hline
\end{tabular}

Mean (SD)

incubated with an antibody against GSTO1-1 and negative control samples with Zymed Rabbit Isotype Control and PBS, and stained with AEC (Zymed Laboratories Inc.) and thereafter with Mayer's haematoxylin.

\section{Western blot analysis}

Western blot analysis from tissue homogenates and sputum supernatants was conducted as described earlier [22] with 1:2000-1:5000 dilution of GSTO1-1 antibody. In previous studies from our laboratory and others $[17,26,27] \beta$-actin has shown high individual variability, especially in tissue samples from the diseased lung. Instead of using $\beta$-actin as a loading control, the protein concentration was measured carefully as triplicates and equal loading was ensured by staining the blotted membranes with Ponceau S (Sigma Aldrich, St. Louis, MO, USA).

\section{Statistical methods}

The statistical analyses were performed with the SPSS for Windows software (SPSS, Chicago, IL, USA). Continuous data were compared using analysis of variance (ANOVA). When ANOVA results indicated that groups differed, post hoc comparisons were performed using two-tailed t-tests. Categorical data were compared using Fisher's exact test designed for small sample groups. P-values less than 0.05 were considered statistically significant. Correlations to lung functions were analyzed with the Pearson correlation test.

\section{Ethical considerations}

The study protocol was approved by the ethical committees of Oulu University Hospital and Helsinki University Hospital and it is in accordance with the ethical standards of the Helsinki declaration of 1975.

\section{Results}

\section{Immunohistochemistry from the tissue specimens}

GSTO1-1 was mainly expressed in alveolar macrophages (Figure 1). One typical feature of COPD is the accumulation of macrophages to the lung. Probably due to the low numbers of the cases and high variability in the numbers of alveolar macrophages, the post-hoc comparison was significant only between non-smokers and stage I-II COPD. (Figure 2A)

The number of GSTO1-1 positive macrophages/surface area $\left(\mathrm{mm}^{2}\right)$ were then evaluated, but the percentages of GSTO1-1 positive macrophages did not differ between non-smokers, smokers and COPD-patients $(\mathrm{p}=0.085)$. When the COPD group was divided into stages I-II and IV COPD, the difference between the groups was significant $(\mathrm{p}=0.004)$. The mean (SD) percentage of GSTO1-1 positive macrophages in non-smokers was 40 (30), smokers 19 (25), COPD stage I-II 24 (26) and COPD stage IV 58 (36) and the mean difference was significant at 0.05 level between stage IV COPD and smokers and between stage IV and stage I-II COPD (Figure 2B). The intensity of the GSTO1-1 immunoreactivity in alveolar macrophages varied, being moderate/intense in 8/16 non-smokers, 9/22

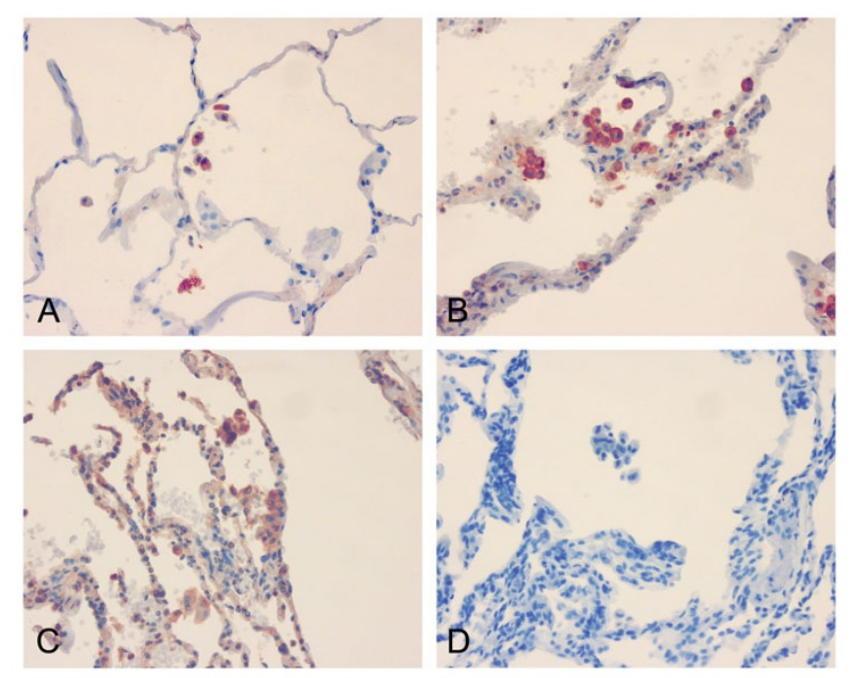

\section{Figure I}

Immunohistochemical staining for GSTOI-I (I:200) in the peripheral lung of non-smoker (A), COPD stage I-II (B) and COPD stage IV (C). Negative control, COPD stage IV (D). GSTOI-I was mainly expressed in alveolar macrophages. 


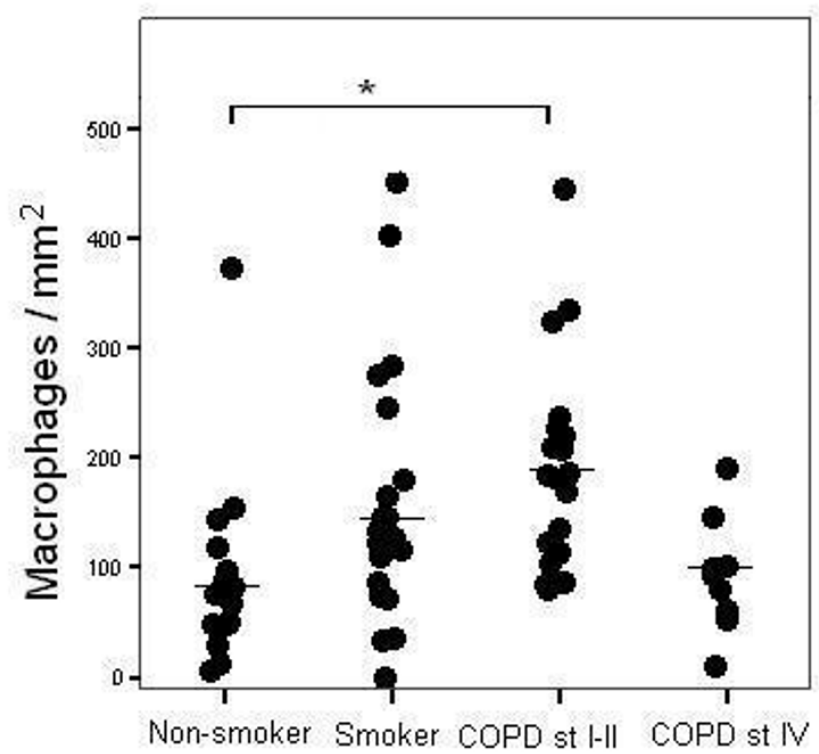

A

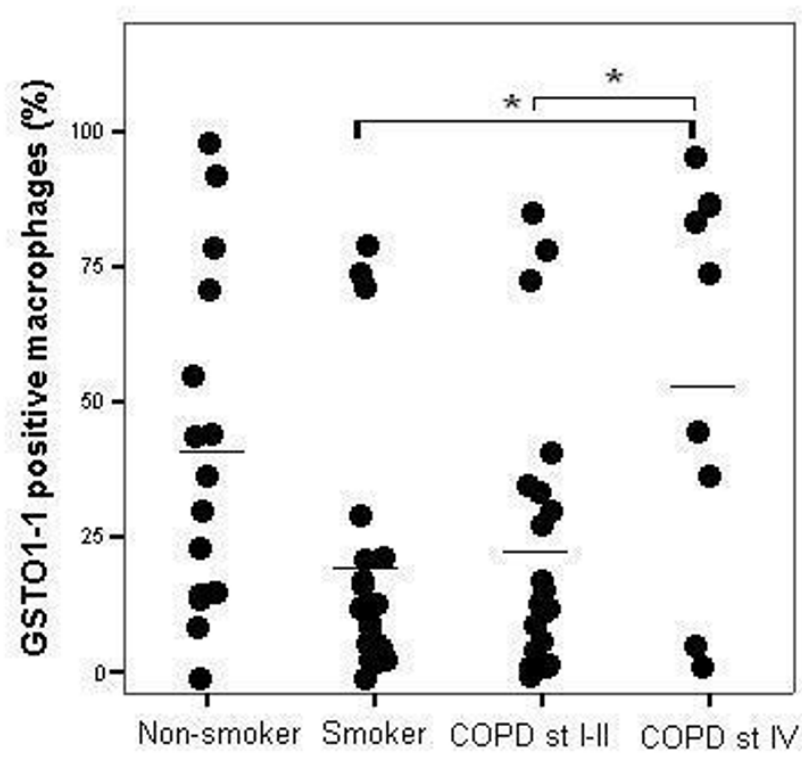

B

\section{Figure 2}

A. The numbers of alveolar macrophages were increased in smokers and in stage I-II COPD compared to non-smokers and stage IV COPD $(P=0.009)$. The post-hoc comparison was significant at 0.05 level between non-smokers and stage I-II COPD $(*)$. B. The mean percentage of GSTOI-I positive macrophages was higher in severe stage IV COPD compared to smokers or COPD stage I-II $(p=0.004)$. The difference between non-smokers and other groups was not statistically significant. The posthoc comparison was significant at 0.05 level between stage IV COPD and smokers and between stage IV and stage I-II COPD $(*)$.

smokers and 23/31 COPD-patients. Bronchial and bronchiolar epithelium was either negative or weak (65) 69), but by immunohistochemistry the alveolar epithelium was always positive in stage IV COPD. The intensities of GSTO1-1 in various lung cells in healthy and diseased lung including all stages of COPD are shown in Figure 3.

There was a negative correlation between FEV1 and \% of GSTO1-1 positive macrophages in all COPD cases $(\mathrm{r}=-$ 0.533, $\mathrm{p}=0.002)$ and in severe COPD $(\mathrm{r}=-0.794, \mathrm{p}=$ $0.011)$. There was no correlation between the pack-years or the dosage of inhaled corticosteroid and percentage of GSTO1-1 positive macrophages.

\section{Induced sputum extracellular fluids and tissue homogenates}

Macrophages in the induced sputum exhibited positive GSTO1-1 reactivity (Figure 4) while neutrophils and lymphocytes were negative. Importantly GSTO1-1 could

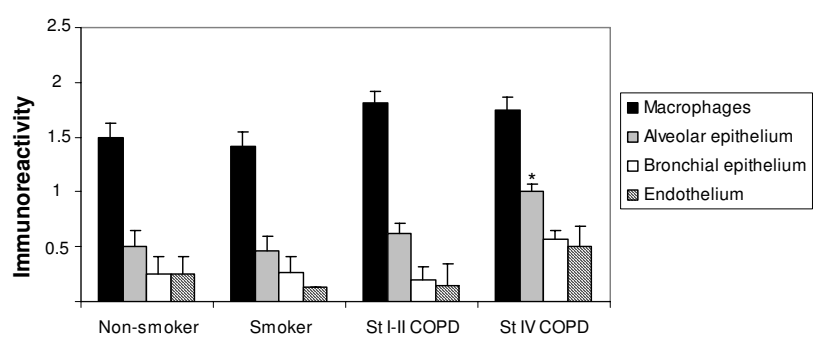

Figure 3

The GSTOI-I immunoreactivity was most prominent in alveolar macrophages varying from negative to moderate/intense and GSTOI-I expression was either absent or weak in other cell types. Alveolar epithelium was always positive in stage IV COPD. Bars represent means, error bars standard error of mean. 


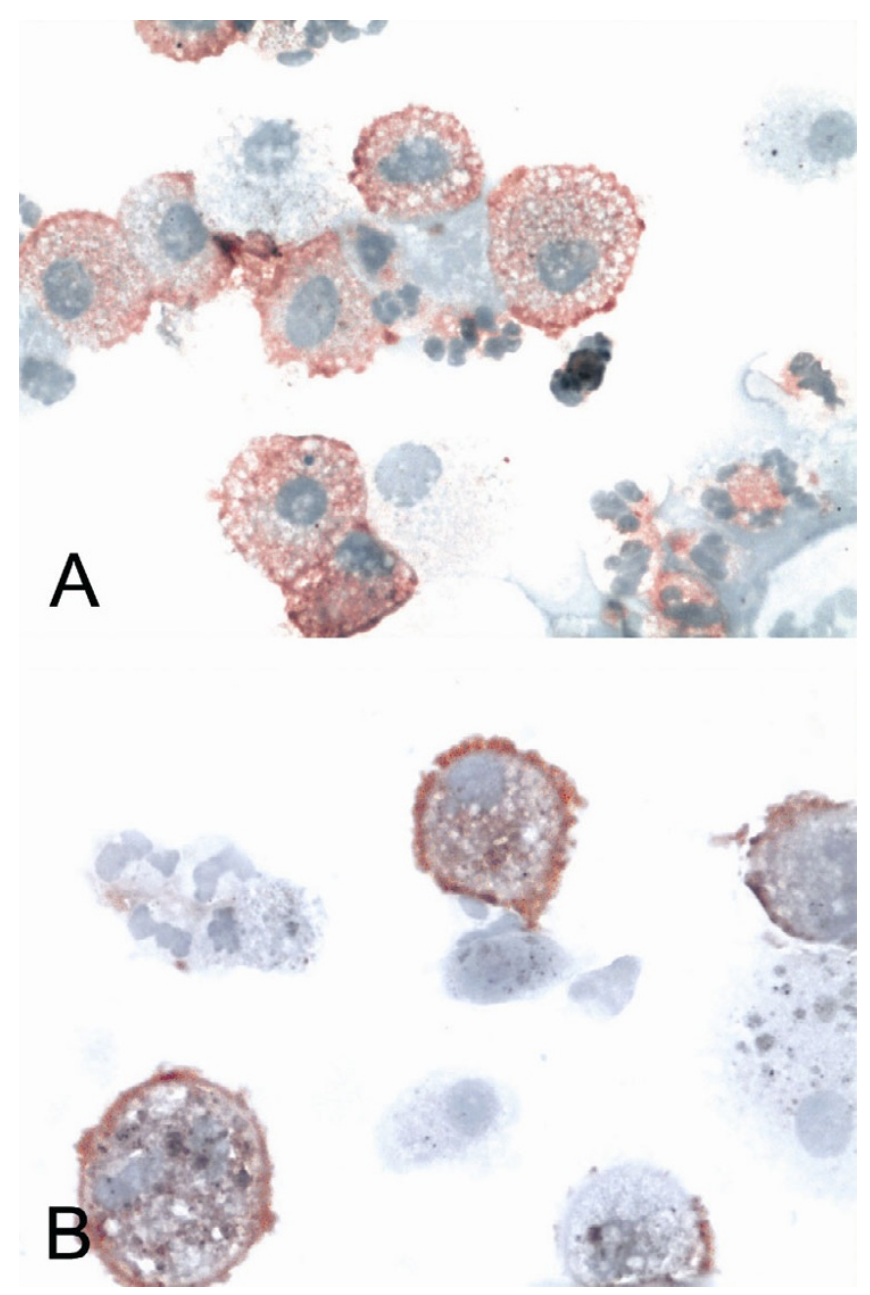

Figure 4

Macrophages in induced sputum exhibited positive GSTOI-I reactivity. Representative sputum cytospins from a smoker (A) and stage II COPD (B) are shown.

also be detected in the sputum supernatants while intracellular markers such as $\beta$-actin and some other antioxidant enzymes such as manganese superoxide dismutase in these specimens were negative (not shown). Western blot analysis for GSTO1-1 showed decreased levels of GSTO11 in the supernatants of COPD patients compared to nonsmokers $(\mathrm{p}=0.023)$ (Figure $5 \mathrm{~A})$. These results suggest that GSTO1-1 is excreted to the extracellular fluids both in healthy lung and COPD.

To confirm the presence of GSTO1-1 in extracellular fluids, GSTO1-1 was analyzed also from plasma and BALF samples of non-smokers and smokers and from the mediums of the cell cultures (U937 and BEAS2B). GSTO1-1 could be detected in all of samples (representative samples are shown in Figure 5B,5C). Tissue homogenates that contain both lung cells and extracellular matrix, exhibited
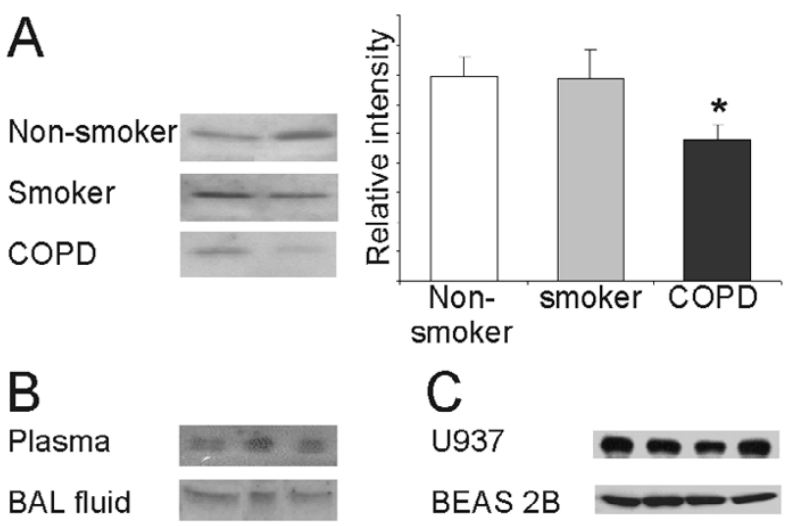

U937

BEAS 2B
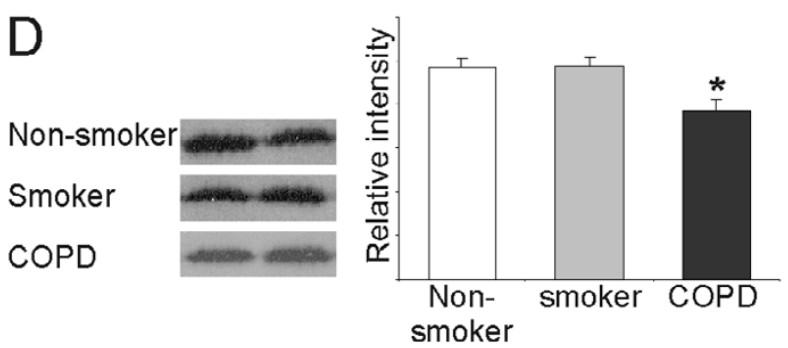

Figure 5

A. Western blotting for GSTOI-I in induced sputum of nonsmokers, smokers and COPD-patients showed an decreased immunoreacitivity in patients with COPD compared to nonsmokers $(P=0.023)$. B. GSTOI-I could be detected in the plasma samples and bronchoalveolar lavage fluid. Representative Western blots from three non-smokers are shown. C. GSTO I-I was also expressed in the culture medium of U937 monocytes and BEAS-2B cells. D. Lung tissue homogenates showed higher level of GSTOI-I in the specimens obtained from non-smokers or smokers with normal lung function when compared to COPD, $\mathrm{p}=0.003$.

a lower level of GSTO1-1 in the specimens obtained from the COPD cases compared to the non-smokers and smokers with normal lung function ( $p=0.003$ ) (Fig 5D). In Western analysis, there was no correlation between the lung function parameters and relative intensity in the lung homogenates

\section{Discussion}

Glutathione related mechanisms that function both intraand extracellularly are known to be crucial in the pulmonary defense against oxidants and probably also against cigarette smoke. Here we show that GSTO1-1 has a highly specific localization in the lung, being expressed mainly in alveolar macrophages, but also weakly in other cell types such as airway/alveolar epithelial cells. Importantly GSTO1-1 could also be detected in extracellular fluids including sputum supernatants, BALF, plasma and the cell culture mediums of cultured monocytes and bronchial epithelial cells. This finding strongly supports the idea 
that the regulation of the GSH homeostasis is not only regulated by intracellular antioxidant enzymes, but is associated with extracellular thiol-modulating proteins that participate in GSH binding and release.

Previously the distribution of GSTO1-1 has been investigated in one human study [21] which showed it to be abundant in a wide range of normal tissues, particularly in the liver but also in the lung (three specimens); in the lung GSTO1-1 could be found only in macrophages. The results of the present study are in line with these findings, but also found GSTO1-1 immunoreactivity in the bronchial and alveolar epithelium. The immunoreactivity was also confirmed in BEAS-2B bronchial epithelial cells in culture.

GSTO1-1 was also detectable in extracellular fluids such as induced sputum supernatants, BALF, plasma and cell culture mediums. Previous studies have already indicated that GSTO1-1 is highly expressed in the liver, suggesting that plasma GSTO1-1 positivity may also be associated with hepatic secretion. All sputum and BALF supernatants were positive for GSTO1-1, but negative for several other markers of intracellular proteins including $\beta$-actin. Over $80 \%$ of the cells were viable which also argues against any leakage of GSTO1-1 through damaged cell membranes. It is therefore possible that GSTO1-1 is similar to Grx1, in being able to be excreted into the airways where it can participate in the maintenance of GSH homeostasis. GSH levels are increased in the BAL fluid representing epithelial lining fluid (ELF) of cigarette smokers [28], but decreased in the ELF during COPD exacerbations [29]. At present the regulation of GSH in the airway secretions/ELF is far from clear, but GSH synthesis in the ELF is very unlikely to occur. Significant amounts of GSH may be present, however, as protein-GSH mixed disulfides that are known to accumulate during oxidative stress both intracellularly and to the extracellular space [30]. GSTO1-1 is one potential enzyme capable of participating in these reactions: it contains cysteine in its active site where Cys32 can form a disulphide bond with GSH and thereby function as a potential reservoir of GSH during oxidative stress. Previous structural studies have indicated that the active site of GSTO1-1 is relatively open and could potentially accommodate glutathionylated protein structures [31] though the capacity of these reactions is probably diminished in COPD. Overall the regulation of GSH maintenance, binding of GSH to proteins, its oxidation and release is complicated. This study significantly extends earlier observations on these pathways and importance of extracellular fluids in these reactions; summary of these reactions has been gathered to Figure 6 .

Tissue studies showed elevated percentage of GSTO1-1 positive macrophages in peripheral lung in severe COPD compared to smokers or stage I-II COPD with negative correlation to lung function parameters. Furthermore, alveolar epithelium was always found to be GSTO1-1 positive in severe COPD. These results may refer to continuing efforts to protect inflamed, remodelled alveolar epithelium and possibly also macrophages against oxidative stress. Overall the synthesis/level of GSTO1-1 may be enhanced in smoker's lung/COPD but together with other antioxidant enzymes is not sufficient to maintain adequate levels of free GSH against oxidative stress.

Tissue homogenates that contain both the cells and matrix showed decreased levels of GSTO1-1 in COPD. These changes in the GSTO1-1 levels in COPD may be partly associated both with decreased levels of macrophages in severe COPD, but also with the presence of all tissue com-

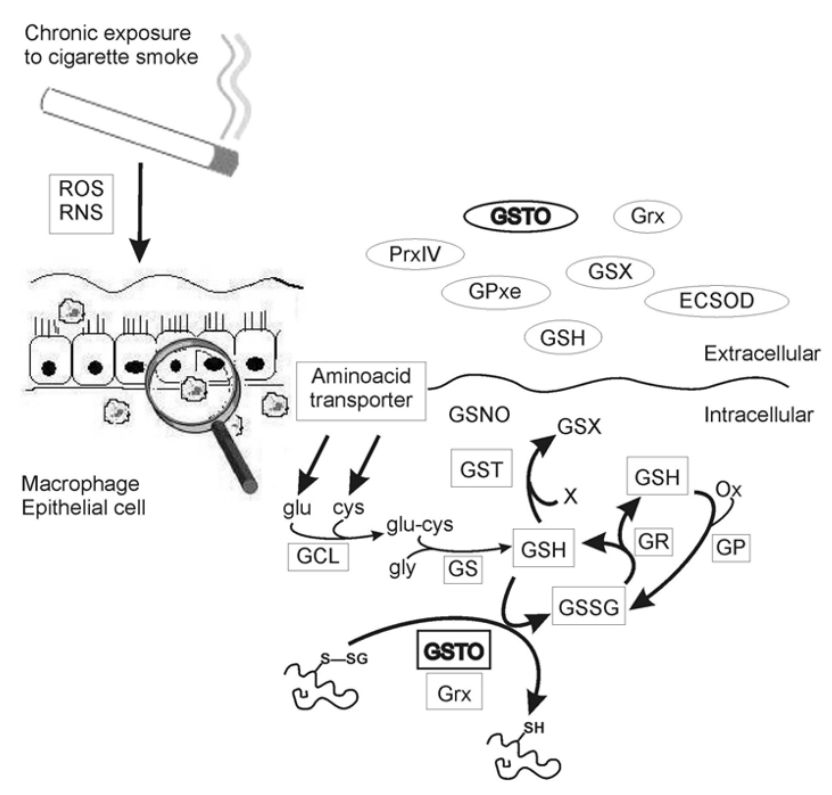

Figure 6

Suggested role of GSTO (glutathione transferase omega) in cigarette smoke induced oxidative stress. Enzymes maintaining GSH homeostasis are important in protecting lung against cigarette smoke induced oxidative stress. GSTO belongs to the glutathione-S-transferase family (GST) that detoxifies toxic substrates present in tobacco smoke by a GSHdependent mechanism. GSTO contains an N-terminal glutathione-binding domain and is able to bind and release GSH. GSH is one of the major antioxidants in airway secretions, and it can be hypothesized that GSTO participates in the maintenance of GSH homeostasis not only intracellularly but also in the extracellular space. ROS, reactive oxygen species; RNS, reactive nitrogen species; GSH, reduced glutathione; GSSG, oxidized glutathione; GR glutathione reductase; GCL, glutamate cysteine ligase; Grx, glutaredoxin; Prxe, peroxiredoxin, GPXe, glutathione peroxidase (extracellular); GSX, glutathione; ECSOD, extracellular superoxide dismutase; GSNO, nitrosoglutathione; GS, glutathione syntethase. 
ponents including the matrix in the lung homogenates and lowered GSTO1-1 levels in the extracellular space.

In summary, this study significantly extends earlier understanding about the antioxidant defence in human lung and extracellular fluids. The important new finding of the presence of GSTO1-1 in extracellular fluids will require further investigation to elucidate the role of GSTO1-1 there since the regulation of GSH levels in these fluids is still poorly understood. The regulation of GSTO is also unknown and there is no literature concerning the effect of oxidative stress on GSTO expression. This is also a critical area requiring research in future investigations.

\section{Competing interests}

The authors declare that they have no competing interests. The study has not been supported by tobacco industry.

\section{Authors' contributions}

THH participated in the design of the study and selection of patient material, performed part of the statistical analysis and drafted the manuscript. MJP carried out the Western blotting studies, participated in analyzing the immunohistochemical data, performed part of the statistical analysis and helped to draft the manuscript. PHR participated in selection and collection of patient material, analyzing the immunohistochemical results and performed part of the statistical analysis. YS and KMS participated in selection of patient material and analyzing the immunohistochemical results. PGB participated in the design of the study, provided the antibody against GSTO1-1 and helped to draft the manuscript. LWR participated in study coordination and helped to draft the manuscript. VLK conceived the study, and participated in its design and coordination and helped to draft the manuscript. All authors have read and approved the final manuscript.

\section{Acknowledgements}

This work was supported by grants from the Finnish Anti-Tuberculosis Association Foundation, Finnish Association of Respiratory Medicine, Sigrid Juselius Foundation, Ahokas Foundation, the Australian National Health and Medical Council, the Academy of Finland, the Magnus Ehrnrooth Foundation, the Finnish Cultural Foundation and the Funding of Helsinki University Hospital (HUCH EVO). We are grateful to Ms Kirsi Kvist-Mäkelä, Ms Tiina Marjomaa, Ms Heta Merikallio and Mr Manu Tuovinen for their excellent technical assistance.

\section{References}

I. Langen RC, Korn SH, Wouters EF: ROS in the local and systemic pathogenesis of COPD. Free Radic Biol Med 2003, 35:226-235.

2. Rahman I, MacNee W: Role of oxidants/antioxidants in smoking-induced lung diseases. Free Radic Biol Med I 996, 2 I:669-68I.

3. Golpon HA, Coldren CD, Zamora MR, Cosgrove GP, Moore MD, Tuder RM, Geraci MW, Voelkel NF: Emphysema lung tissue gene expression profiling. Am J Respir Cell Mol Biol 2004, 3 I:595-600.

4. Hackett NR, Heguy A, Harvey BG, O'Connor TP, Luettich K, Flieder DB, Kaplan R, Crystal RG: Variability of antioxidant-related gene expression in the airway epithelium of cigarette smokers. Am J Respir Cell Mol Biol 2003, 29:33 I-343.

5. Harju T, Kaarteenaho-Wiik R, Soini $Y$, Sormunen R, Kinnula VL: Diminished immunoreactivity of gamma-glutamylcysteine synthetase in the airways of smokers' lung. Am J Respir Crit Care Med 2002, 166:754-759.

6. Kinnula VL, Crapo JD: Superoxide dismutases in the lung and human lung diseases. Am J Respir Crit Care Med 2003, 167:1600-1619.

7. Kinnula VL: Focus on antioxidant enzymes and antioxidant strategies in smoking related airway diseases. Thorax 2005, 60:693-700.

8. Yoneda K, Chang MM, Chmiel K, Chen Y, Wu R: Application of high-density DNA microarray to study smoke- and hydrogen peroxide-induced injury and repair in human bronchial epithelial cells. J Am Soc Nephrol 2003, I4:S284-S289.

9. Cantin AM, North SL, Hubbard RC, Crystal RG: Normal alveolar epithelial lining fluid contains high levels of glutathione. J Appl Physiol 1987, 63:152-157.

10. Rahman I, Morrison D, Donaldson K, MacNee W: Systemic oxidative stress in asthma, COPD, and smokers. Am J Respir Crit Care Med 1996, 154: 1055-1060.

II. Rahman I, MacNee W: Lung glutathione and oxidative stress: implications in cigarette smoke-induced airway disease. Am J Physiol 1999, 277:LI067-LI088.

12. Rahman I, Smith CA, Lawson MF, Harrison DJ, MacNee W: Induction of gamma-glutamylcysteine synthetase by cigarette smoke is associated with AP-I in human alveolar epithelial cells. FEBS Lett 1996, 396:21-25.

13. Neurohr C, Lenz AG, Ding I, Leuchte H, Kolbe T, Behr J: Glutamate-cysteine ligase modulatory subunit in BAL alveolar macrophages of healthy smokers. Eur Respir J 2003, 22:82-87.

14. Rahman I, van Schadewijk AA, Hiemstra PS, Stolk J, van Krieken JH, MacNee W, de Boer WI: Localization of gamma-glutamylcysteine synthetase messenger rna expression in lungs of smokers and patients with chronic obstructive pulmonary disease. Free Radic Biol Med 2000, 28:920-925.

15. Singh A, Rangasamy T, Thimmulappa RK, Lee H, Osburn WO, Brigelius-Flohe R, Kensler TW, Yamamoto M, Biswal S: Glutathione peroxidase 2, the major cigarette smoke-inducible isoform of GPX in lungs, is regulated by Nrf2. Am J Respir Cell Mol Biol 2006, 35:639-650.

16. Comhair SA, Lewis MJ, Bhathena PR, Hammel JP, Erzurum SC: Increased glutathione and glutathione peroxidase in lungs of individuals with chronic beryllium disease. Am J Respir Crit Care Med 1999, 159:1824-1829.

17. Peltoniemi MJ, Rytila PH, Harju TH, Soini YM, Salmenkivi KM, Ruddock LW, Kinnula VL: Modulation of glutaredoxin in the lung and sputum of cigarette smokers and chronic obstructive pulmonary disease. Respir Res 2006, 7:133.

18. Lundberg M, Fernandes AP, Kumar S, Holmgren A: Cellular and plasma levels of human glutaredoxin $I$ and 2 detected by sensitive ELISA systems. Biochem Biophys Res Commun 2004, 319:801-809.

19. Nakamura H, Vaage J, Valen G, Padilla CA, Bjornstedt M, Holmgren $A$ : Measurements of plasma glutaredoxin and thioredoxin in healthy volunteers and during open-heart surgery. Free Radic Biol Med 1998, 24: I 176-I I86.

20. Whitbread AK, Masoumi A, Tetlow N, Schmuck E, Coggan M, Board PG: Characterization of the omega class of glutathione transferases. Methods Enzymol 2005, 40 1:78-99.

21. Yin ZL, Dahlstrom JE, Le Couteur DG, Board PG: Immunohistochemistry of omega class glutathione S-transferase in human tissues. J Histochem Cytochem 200I, 49:983-987.

22. Peltoniemi M, Kaarteenaho-Wiik R, Saily M, Sormunen R, Paakko P, Holmgren A, Soini Y, Kinnula VL: Expression of glutaredoxin is highly cell specific in human lung and is decreased by transforming growth factor-beta in vitro and in interstitial lung diseases in vivo. Hum Pathol 2004, 35:1000-1007.

23. Pauwels RA, Buist AS, Calverley PM, Jenkins CR, Hurd SS: Global strategy for the diagnosis, management, and prevention of chronic obstructive pulmonary disease. NHLBI/WHO Global Initiative for Chronic Obstructive Lung Disease (GOLD) Workshop summary. Am J Respir Crit Care Med 200I, 163:1256-1276 
24. Djukanovic R, Sterk PJ, Fahy JV, Hargreave FE: Standardised methodology of sputum induction and processing. Eur Respir J Suppl 2002, 37: Is-2s.

25. Sundstrom C, Nilsson K: Establishment and characterization of a human histiocytic lymphoma cell line (U-937). Int J Cancer 1976, 17:565-577.

26. Glare EM, Divjak M, Bailey MJ, Walters EH: beta-Actin and GAPDH housekeeping gene expression in asthmatic airways is variable and not suitable for normalising mRNA levels. Thorax 2002, 57:765-770.

27. Ishii T, Wallace AM, Zhang X, Gosselink J, Abboud RT, English JC, Pare PD, Sandford AJ: Stability of housekeeping genes in alveolar macrophages from COPD patients. Eur Respir J 2006, 27:300-306.

28. Morrison D, Rahman I, Lannan S, MacNee W: Epithelial permeability, inflammation, and oxidant stress in the air spaces of smokers. Am J Respir Crit Care Med 1999, 159:473-479.

29. Drost EM, Skwarski KM, Sauleda J, Soler N, Roca J, Agusti A, MacNee $\mathrm{W}$ : Oxidative stress and airway inflammation in severe exacerbations of COPD. Thorax 2005, 60:293-300.

30. Cotgreave IA, Gerdes RG: Recent trends in glutathione biochemistry--glutathione-protein interactions: a molecular link between oxidative stress and cell proliferation? Biochem Biophys Res Commun 1998, 242:1-9.

31. Board PG, Coggan M, Chelvanayagam G, Easteal S, Jermiin LS, Schulte GK, Danley DE, Hoth LR, Griffor MC, Kamath AV, Rosner MH, Chrunyk BA, Perregaux DE, Gabel CA, Geoghegan KF, Pandit J: Identification, characterization, and crystal structure of the Omega class glutathione transferases. J Biol Chem 2000, 275:24798-24806.

Publish with Bio Med Central and every scientist can read your work free of charge

"BioMed Central will be the most significant development for disseminating the results of biomedical research in our lifetime. "

Sir Paul Nurse, Cancer Research UK

Your research papers will be:

- available free of charge to the entire biomedical community

- peer reviewed and published immediately upon acceptance

- cited in PubMed and archived on PubMed Central

- yours - you keep the copyright

Submit your manuscript here:

http://www.biomedcentral.com/info/publishing_adv.asp 